\title{
Sites of Synthesis of Urokinase and Tissue-Type Plasminogen Activators in the Murine Kidney
}

\author{
André-Pascal Sappino, ${ }^{\star}$ Joaquin Huarte, Jean-Dominique Vassalli, and Dominique Belin \\ ${ }^{*}$ Division of Onco-Haematology, Institute of Histology and Embryology, and ${ }^{\ddagger}$ Department of Pathology, \\ University of Geneva Medical School, 1211 Geneva 4, Switzerland
}

\begin{abstract}
Kidneys have long been recognized as a major source of plasminogen activators (PAs). However, neither the sites of synthesis of the enzymes nor their role in renal function have been elucidated. By the combined use of zymographies on tissue sections and in situ hybridizations, we have explored the cellular distribution of urokinase-type (u-PA) and tissue-type (t-PA) plasminogen activators and of their mRNAs in developing and adult mouse kidneys. In 17.5-d old embryos, renal tubules synthesize u-PA, while S-shaped bodies produce t-PA. In the adult kidney, u-PA is synthesized and released in urine by the epithelial cells lining the straight parts of both proximal and distal tubules. In contrast, t-PA is produced by glomerular cells and by epithelial cells lining the distal part of collecting ducts. The precise segmental distribution of PAs suggests that both enzymes may be implicated in the maintenance of tubular patency, by catalyzing extracellular proteolysis to prevent or circumvent protein precipitation. (J. Clin. Invest. 1991. 87:962970.) Key words: embryo - in situ hybridization - nephron • mouse $\cdot$ proteolysis
\end{abstract}

\section{Introduction}

Plasminogen activators (PAs) ${ }^{1}$ are serine proteases that convert plasminogen, a widely distributed zymogen, into plasmin, a trypsin-like protease of broad specificity. Two types of PAs have been identified in mammalian cells: they are produced from two related but distinct genes and are referred to as u-PA (urokinase-type) and t-PA (tissue-type) (1-3). Though they share similar catalytic activities, u-PA and t-PA differ in their $M_{\mathrm{r}}$, immunological reactivities, and interactions with other proteins, such as extracellular matrix components and cell surface binding sites. u-PA, which is produced and secreted by a variety of cell types, including monocytes/macrophages $(4,5)$, trophoblasts $(6,7)$, and epithelial cells (for review see 2 ), is considered to participate in the extracellular proteolysis accompanying tissue remodeling and cellular invasion $(1,2,8)$. In contrast, t-PA, which has a high affinity for fibrin $(9,10)$ and

Address reprint requests to Dr. A.-P. Sappino, Division of Onco-Hematology, Centre Medical Universitaire, 1 rue Michel-Servet, $1211 \mathrm{Ge-}$ neva 4, Switzerland.

Received for publication 8 August 1990 and in revised form 26 October 1990.

1. Abbreviations used in this paper: PA, plasminogen activator; u-PA, urokinase-type PA; t-PA, tissue-type PA.

J. Clin. Invest.

(c) The American Society for Clinical Investigation, Inc.

0021-9738/91/03/0962/09 \$2.00

Volume 87, March 1991, 962-970 which is synthesized by endothelial cells in normal blood vessels (11), is thought to be predominantly involved in fibrinolysis.

There is abundant experimental evidence to implicate PAs in the renal biology of mammals. Indeed, the first PA to be identified was from human urine, which led to its denomination as urokinase (12). Epithelial cell lines derived from renal tissues of various mammalian species have since been shown to synthesize and release u-PA $(13,14)$. Immunohistochemical studies performed on mouse tissues have localized u-PA immunoreactivity to renal tubules(15), while biochemical and immunohistochemical investigations have detected mainly t-PA, but also u-PA, in human glomeruli (16-18). These cumulated observations suggest that PAs might fulfill essential functions in the urinary tract. However, in the aforementioned studies, the cellular sites of synthesis for PAs were not precisely determined: since PAs are secreted proteins, which can interact with extracellular matrix components $(9,19)$, cell surface receptors $(20,21)$, and specific inhibitors $(5,8,22-24)$, localization data based on protein estimations are difficult to interpret.

To assess the cellular localizations of u-PA and t-PA mRNAs during mouse nephrogenesis and in the adult kidney, we performed in situ hybridizations on cryostat tissue sections, with specific cRNA probes for u-PA and t-PA. Concomitantly, we applied to corresponding tissue sections a highly sensitive zymographic assay, which allows the detection of PA enzymatic activities at the histological level. We report here that u-PA and t-PA are synthesized and released in urine by distinct portions of the urinary tubules, and that a compartmentalized distribution of PAs is already apparent in embryonic kidneys.

\section{Methods}

Material. Kidneys, ureters, and bladders were collected from adult NMRI mice, dissected, embedded in Tissue-Tek (Miles Ames Div., Elkhart, IN), frozen down in precooled methylbutane, and stored at $-70^{\circ} \mathrm{C}$. Excreted urine was obtained from urethral discharge after animal handling. Pelvic urine was collected through the renal pelvis of anesthesized animals with a glass pipette after ureteral ligature.

Pregnant mice were killed on days 15 and 17 of gestation to obtain 15.5 and 17.5-d old embryos (25). Embryos were dissected from the uteri, embedded, and stored as above.

Enzymatic analyses. Protein extraction, immunoprecipitation, gel electrophoresis, and zymography were performed as described (26).

For zymographies on cryostat tissue sections, the overlay mixture (27) consisted of: $0.5 \mathrm{ml}$ of an $8 \%$ commercial instant nonfat dry milk solution (the $8 \%$ stock solution in PBS was heated at $95^{\circ} \mathrm{C}$ for $30 \mathrm{~min}$, centrifuged $10 \mathrm{~min}$ at $3,000 \mathrm{~g}$, and the supernatant collected), $0.75 \mathrm{ml}$ of PBS (with $0.9 \mathrm{mM} \mathrm{Ca}^{++}$and $1 \mathrm{mM} \mathrm{Mg}^{++}$), $0.7 \mathrm{ml}$ of a $2.5 \%$ agar solution in water, and $20 \mu \mathrm{l}$ of a $4 \mathrm{mg} / \mathrm{ml}$ solution of purified human plasminogen. This overlay mixture was prepared at $50^{\circ} \mathrm{C}$ and $100 \mu \mathrm{l}$ were applied to prewarmed $10 \mu \mathrm{m}$ thick cryostat tissue sections mounted on poly-L-lysine-coated slides, and spread evenly under 24 $\times 32 \mathrm{~mm}$ glass coverslips. Slides were incubated at $37^{\circ} \mathrm{C}$ in humid 
chambers and zymograms were allowed to develop for 2-6 h. Identical experiments were carried out with overlay mixtures from which plasminogen was omitted or to which were added either $1 \mathrm{mM}$ amiloride (28), nonimmune goat or rabbit sera, specific anti-u-PA sera (rabbit anti-mouse u-PA serum, final dilution 1/50) (29), or specific anti-t-PA sera (goat anti-human t-PA serum, final dilution $1 / 50$, provided by Dr. W. Schleuning, Berlin). The specificities of antibodies were verified by caseinolytic assays in solution using the conditioned medium of MSVtransformed $3 \mathrm{~T}_{3}$ cells as a source of murine u-PA (30) and the conditioned medium of PYS cells as a source of murine t-PA (29). Photographs were taken using dark-ground illumination.

Plasmid constructions, in vitro transcriptions, and Northern blot analysis. The u-PA antisense probe prepared from pSP64-MU, containing the 658-bp Pst I-Hind III fragment of the mouse u-PA cDNA clone pDB29 (31), and the t-PA antisense probe from pSP64-MT ${ }_{3}$, containing the 726-bp Pvu II-Spe I fragment of the mouse t-PA cDNA clone pUC9-A33 (32), were transcribed in vitro in the presence of 12.5 $\mu \mathrm{M}$ of $\alpha\left[{ }^{32} \mathrm{P}\right]$ labeled UTP (uridine 5'-triphosphate, $400 \mathrm{Ci} / \mathrm{mmol}$; Amersham International, Amersham, UK) or $30 \mu \mathrm{M}\left[{ }^{3} \mathrm{H}\right]$ labeled UTP and $30 \mu \mathrm{M}\left[{ }^{3} \mathrm{H}\right.$ ]labeled CTP (cytidine 5'-triphosphate, 40 and $20 \mathrm{Ci} /$ mmol, respectively; Amersham International). ${ }^{3} \mathrm{H}$-labeled probes were reduced to an average size of $50-100 \mathrm{nt}$ by mild alkaline hydrolysis as previously described (7).

Total RNAs were extracted as described elsewhere (33). RNAs were denatured with glyoxal, electrophoresed in $1.2 \%$ agarose gels, and transferred overnight onto Biodyne nylon membranes (Pall Corp., Glen Cove, NY). Prehybridizations, hybridizations, and posthybridization washes were performed as previously described $(34,35)$.

In situ hybridizations. Minor modifications were brought to the procedure previously described (7). 5-10 $\mu \mathrm{m}$ cryostat tissue sections were mounted on poly-L-lysine (Sigma Chemical Co., St. Louis, MO) coated microscope slides, fixed in 4\% glutaraldehyde in PBS for 1-5 min, rinsed in PBS, and stored in $70 \%$ ethanol at $4^{\circ} \mathrm{C}$ until analyzed. Prehybridizations, hybridizations, and posthybridization washes were carried out as described elsewhere (7). 1-3 $\times 10^{6} \mathrm{cpm}$ of ${ }^{32} \mathrm{P}$-labeled RNAs or $0.4-1 \times 10^{6} \mathrm{cpm}$ of ${ }^{3} \mathrm{H}$-labeled RNAs were applied to each section in 20-70 $\mu \mathrm{l}$ of hybridization mixture (7). After graded ethanol dehydration, sections hybridized to ${ }^{32} \mathrm{P}$-labeled cRNAs were directly exposed to x-ray films (SB5; Eastman Kodak Co., Rochester, NY) between intensifying screens and the films developed after 3-5 d exposure at room temperature, while sections hybridized to ${ }^{3} \mathrm{H}$-labeled $\mathrm{cRNAs}$ were immersed in NTB-2 emulsion (Eastman Kodak), diluted 1:1 in deionized water. After 3-15 wk exposure, they were developed in Kodak D-19 developer, fixed in $30 \% \mathrm{Na}$ thiosulfate, and counterstained in methylene blue.

Controls of specificity have been previously described $(7,35)$, and included Northern blot hybridizations, the use of sense RNA probes and dot blot analysis under conditions of in situ hybridizations. For each experiment, control tissue sections of vas deferens and oviduct were included; these tissues contain, respectively and predominantly, u-PA and t-PA (7). Photographs were taken with a conventional camera (Canon USA Inc., Lake Success, NY), using PANF black and white film (Ilford, Knutsford, Cheshire, England). Microphotographs were taken with a photomicroscope (Zeiss, Oberkochen, FRG), equipped with an immersion dark-field condensor, using Kodak Ektachrome 50 color film.

\section{Results}

Both $u-P A$ and $t-P A$ are synthesized by adult renal tissues and secreted in urine. Samples of urine were analyzed by SDSPAGE followed by zymography. Two predominant types of PA were revealed in excreted urine (Fig. $1 A$, lane 4 ) that were inhibited by amiloride (Fig. $1 B$, lane 4 ), a known inhibitor of urokinase catalytic activity (28), and corresponded to the 48,000 and $28,000-M_{\mathrm{r}}$ species of murine u-PA $(30,36)$. In addition, we observed trace amounts of a $72,000 M_{\mathrm{r}}$ PA (Fig. $1 \mathrm{~A}$,
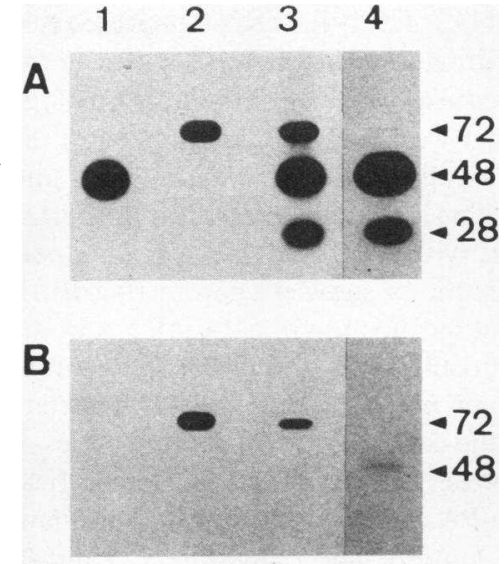

Figure 1. Zymographic analysis of PAs in adult mouse urine. $0.3 \mu \mathrm{l}$ of fresh pelvic (lane 3 ) and excreted (lane 4) urine were analyzed by SDSPAGE and zymography, in the absence $(A)$ or in the presence of $1 \mathrm{mM}$ amiloride in the substrate (B). Murine u-PA (lane l) and t-PA (lane 2) standards. The photographs were taken after $16 \mathrm{~h}$ of incubation at $37^{\circ} \mathrm{C}$. The $28-\mathrm{kD}$ molecular mass species observed in $A$ (lanes 3 and 4 ) correspond to the low molecular mass u-PA $(36,52)$. Molecular masses are indicated on the right (kD) and were calculated according to standard molecular mass markers electrophoresed in an adjacent lane and stained with Coomassie blue.

lane 4 ) that comigrated with murine t-PA (Fig. $1 A$, lane 2). In pelvic urine, approximately equivalent catalytic amounts of $M_{\mathrm{r}}$ $72,000 \mathrm{t}-\mathrm{PA}$ that was not inhibited by amiloride, and $M_{\mathrm{r}}$ 48,000 and 28,000 u-PA were detected (Fig. 1, $A$ and $B$, lane 3). Since t-PA is barely detectable in excreted urine, these findings suggest that t-PA activity is lost during its transit along the excretory pathway. Northern blot analysis of total RNA extracted from adult kidneys confirmed that both PAs can be synthesized by renal tissues, u-PA mRNA representing the predominant species detected, whereas, comparatively, very little signal was found in total RNA extracted from ureters or bladder (Fig. 2). These observations show that both PAs are secreted in urine and support the notion that urinary PAs mainly originate from the kidney.

$u-P A$ and $t-P A$ are synthesized by distinct regions of the adult kidney. To determine the localization of u-PA and t-PA mRNAs at a regional level, we first hybridized whole kidney tissue sections to ${ }^{32} \mathrm{P}$-labeled cRNA probes. The two probes revealed macroscopically circumscribed and distinct distribu-

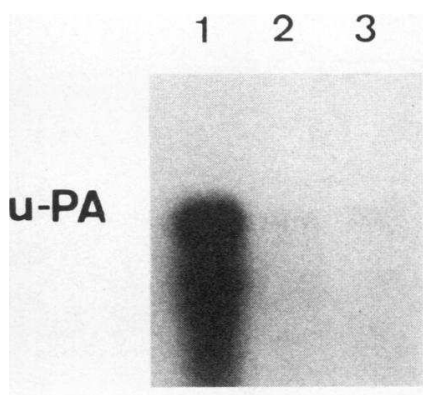

Figure 2. Northern blot analysis of $\mathrm{u}-\mathrm{PA}$ and $\mathrm{t}-\mathrm{PA}$ mRNAs in adult urinary tract tissues. $5 \mu \mathrm{g}$ of total RNA from kidney (lane 1 ), ureter (lane 2 ), and bladder (lane 3) were analyzed using $\mathrm{u}-\mathrm{PA}$ and t-PA cRNA probes. The membranes were exposed together for 18 $h$ at $-80^{\circ} \mathrm{C}$, between intensifying screens. Even loading and the integrity of RNAs were verified by staining membranes after transfer with methylene blue. 
tions of the respective mRNAs. The $\mathrm{u}-\mathrm{PA}$ cRNA probe labeled a well-defined zone of maximal intensity, corresponding to the outer stripe of the outer medulla, with a clear delineation of the medullary rays; a somewhat weaker signal was noticed in the inner stripe of the outer medulla, while the inner medulla and the papilla were negative. No signal was detected in the cortex (Fig. $3 A$ ). Hybridizations with the t-PA cRNA probe, performed on adjacent tissue sections, showed a contrasting distribution, with a predominant localization of t-PA mRNA in the papilla and in the inner medulla, and a weaker expression in the inner stripe of the outer medulla (Fig. $3 \mathrm{~B}$ ). A punctate signal was also evident in the cortex. The relative intensities of the signals obtained on Northern blots and by in situ hybridizations were comparable, u-PA mRNA being more abundant than t-PA mRNA (Fig. 2, $A$ and $B$, lane 1 , and Fig. 3, $A$ and $B$ ) (37). The specificity of in situ hybridizations with these probes has already been established for other murine tissues $(7,35)$; furthermore, in the kidney, the specificity of in situ hybridizations is supported by the nonoverlapping distribution of the signals detected by two probes from related genes.

To assess whether these mRNAs are translated, the expression of PA enzymatic activity was visualized in situ by overlaying corresponding unfixed cryostat tissue sections with an agar solution containing plasminogen and casein. After $1-3 \mathrm{~h}$ of incubation at $37^{\circ} \mathrm{C}$, distinct zones of caseinolysis were observed. Rapid substrate lysis occurred over the outer medulla (Fig. $3 C$ ) that was inhibited by the u-PA inhibitor amiloride (Fig. $3 \mathrm{D}$ ) and anti-u-PA antibodies (Fig. 4, $1 \mathrm{C}$ ). In the presence of amiloride and at later times, additional sites of proteolytic activity were observed over the papilla and glomeruli (Fig. $3 D$ ). This activity was abolished by anti-t-PA antibodies (Fig. $4,2 B$ ), but not by anti-u-PA antibodies (Fig. 4, $1 C$ ). All activities were exclusively detected in the presence of plasminogen (Fig. 4, $1 A$ and $B$ ), confirming that they were due to PAs. These results demonstrate the presence of u-PA in the outer medulla and of t-PA in glomeruli and in the papilla; they correlate with the hybridization studies and indicate that u-PA and t-PA mRNAs are translated.

The specificity of the zymographies on tissue sections used in the present study is supported by the requirement of plasminogen to visualize sites of caseinolysis, the inhibition of ca- seinolytic activities with specific antibodies, and by the colocalizations of caseinolytic activities with mRNA distributions. To distinguish u-PA from t-PA, we found that amiloride was most useful for practical reasons, since it inhibits u-PA catalytic activity as effectively as specific antibodies. Other serine proteases are known to be produced by rodent kidney, such as esterase $A$ (38) and kallikreins (39); although renal kallikreins can be inhibited by amiloride ( 40 ), they have been localized to regions of the nephron $(41,42)$ that differ clearly from those reported here for u-PA.

u-PA $m R N A$ is present in epithelial cells of straight parts of proximal and distal tubules. To identify the sites of u-PA synthesis at the cellular level, tissue sections were hybridized to ${ }^{3} \mathrm{H}$-labeled probes and revealed by emulsion autoradiography. These hybridizations confirmed the restricted distribution of u-PA mRNA observed macroscopically. The epithelial cells from two different types of tubules were found to contain abundant u-PA mRNA (Fig. 5, $A, B, C$, and $E$ ). The first type consisted of cells displaying a brush border, and present in tubules that had, on transverse sections, a large diameter without a visible lumen; these tubules, located in the outer stripe of the outer medulla (Fig. 5, B, $C$, and $E$ ) were identified as the straight parts of proximal tubules; most, but not all, epithelial cells in these tubules were labeled. The second group of tubular cells labeled by the u-PA probe was associated with tubules of smaller diameter, that had a visible lumen on transverse sections ( $I$ and $J$ ), and that were present in the outer (Fig. 5, $A, B$, and $C$ ) and inner stripes (Fig. $5, F, G, H, I$, and $J$ ) of the outer medulla; both their histological appearance and their distribution indicate that they correspond to the straight parts of distal tubules. In the inner stripe of the outer medulla, the labeling of the straight parts of distal tubules appeared to follow a segmental pattern, which could signify that u-PA mRNA is expressed by certain segments within the same tubule, or alternatively, that only a fraction of distal tubules express u-PA mRNA in their straight parts (Fig. $5 F$ ). It is of interest to note that the subcellular localization of autoradiographic grains differed in the two types of tubules: in the proximal tubules labeling was present in the perinuclear cytoplasm of epithelial cells and was absent from the brush border region (Fig. $5 E$ ), while in distal tubules grains were predominantly visualized in the apical por-
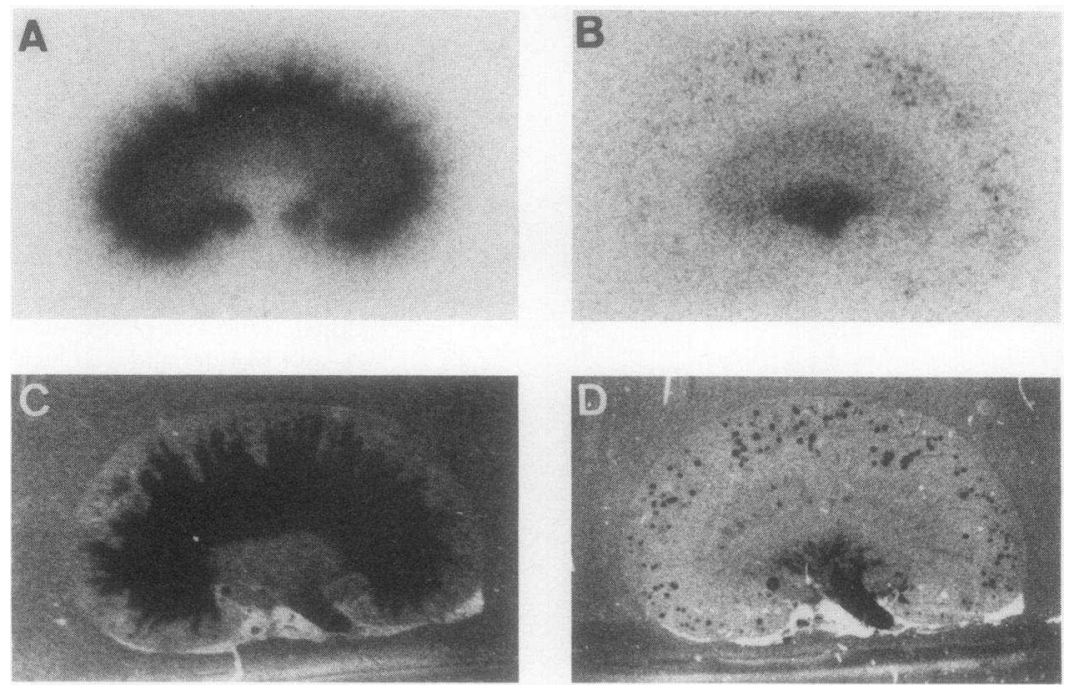

Figure 3. $(A)$ and $(B)$ Regional localization of u-PA $(A)$ and t-PA $(B)$ mRNAs by in situ hybridizations of ${ }^{32} \mathrm{P}$-labeled cRNA probes to cryostat tissue sections of adult kidneys. Photographs were taken after $24 \mathrm{~h}(A)$ and $96 \mathrm{~h}(B)$ exposure at room temperature $(\times 3) .(C)$ and $(D)$ Visualization of PA enzymatic activities by histological zymographies on cryostat tissue sections of adult kidneys. Incubations were performed in the absence $(C)$ or in the presence of $1 \mathrm{mM}$ amiloride $(D)$, which selectively inhibits u-PA (28). Photographs were taken after $2 \mathrm{~h}(C)$ and $5 \mathrm{~h}(D)$ incubations at $37^{\circ} \mathrm{C}(\times 3)$. 

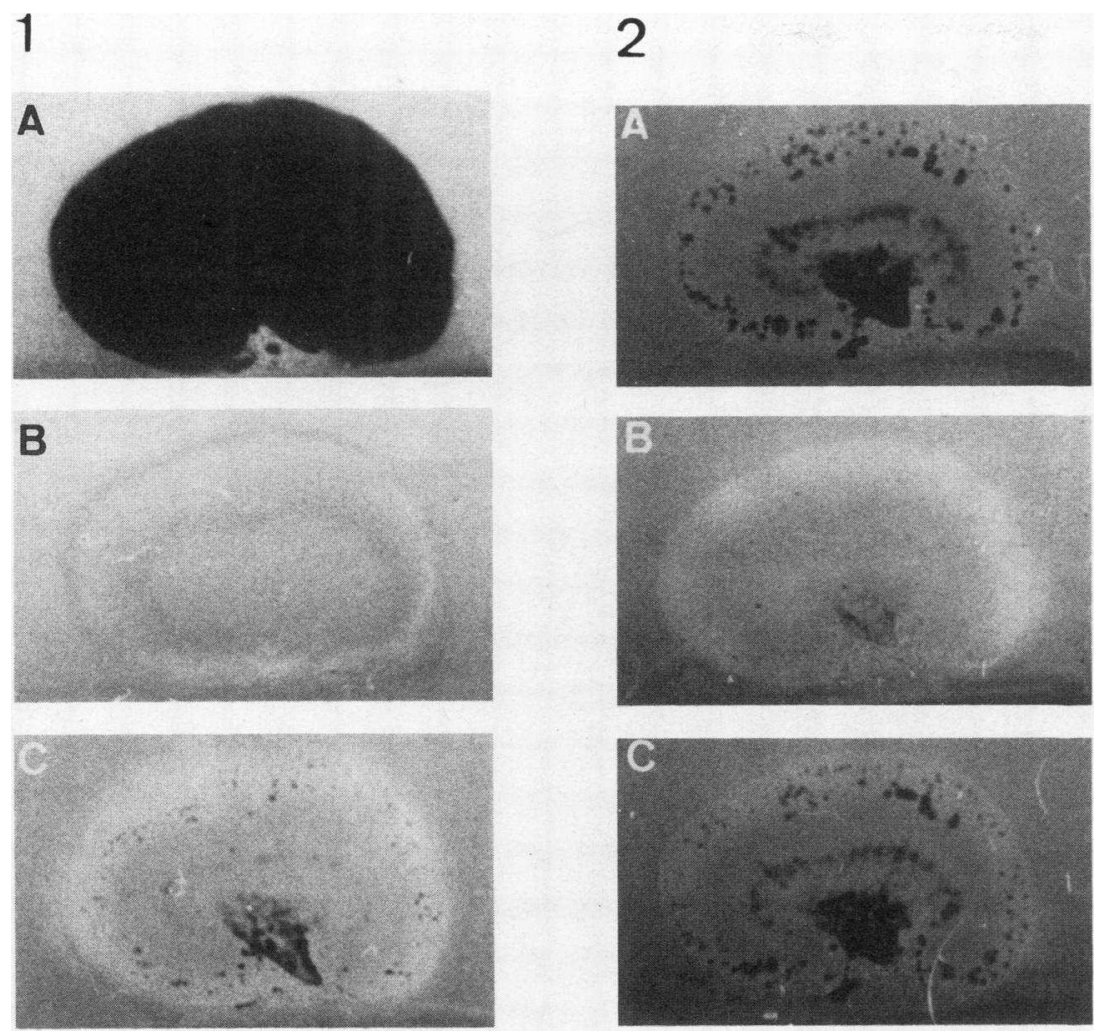

Figure 4. Specificity of histological zymographies performed on adult kidney cryostat tissue sections. (1) Tissue sections were overlaid with an agar-casein solution in the presence $(A)$ or in the absence of plasminogen $(B)$, or in the presence of plasminogen and anti-u-PA antibodies $(C)$. Photographs were taken after $6 \mathrm{~h}$ of incubation at $37^{\circ} \mathrm{C}$. The circumscribed caseinolysis observed after $2 \mathrm{~h}$ shown in Fig. $3 C$ has progressed towards generalized caseinolysis $(A)(\times 3)$. (2) Overlays were performed in the presence of $1 \mathrm{mM}$ amiloride, which inhibits u-PA and allows the selective visualization of t-PA-mediated caseinolysis (28). Tissue sections were overlaid with an agar-casein solution containing plasminogen $(A)$, plasminogen and anti-t-PA antiserum $(B)$, or plasminogen and nonimmune serum $(C)$. Only minimal plasminogen-dependent and amiloride-resistant activity persists in the presence of anti-t-PA antibodies $(B)$. Photographs were taken after $6 \mathrm{~h}$ of incubation at $37^{\circ} \mathrm{C}(\times 3)$. tion of epithelial cells (Fig. 5, $B, C, G, H, I$, and $J$ ); this difference remains presently unexplained. In contrast, convoluted proximal and distal tubules in the cortex were devoid of grains (Fig. 5, $A$ and $D$ ). Similarly, no signal was observed on glomeruli (Fig. $5 A$ ) and on a type of tubules present in the inner stripe of outer medulla (Fig. 5, $G$ and $H$ ) and in the inner medulla (Fig. $5 F$ ), that we interpret as collecting ducts. Though we did not recognize unambiguously Henle's loops in the outer and inner medullae, their potential contribution in u-PA mRNA expression is likely to be minimal, since no positive labeling was observed in the inner medulla, which contains numerous Henle's loops.

t-PA $m R N A$ is present in epithelial cells of distal collecting ducts and in glomerular cells. Hybridizations with the ${ }^{3} \mathrm{H}$-labeled probe confirmed the presence of t-PA mRNA in the inner medulla and in the papilla. Labeling was detected predominantly over epithelial cells lining tubular structures that were concentrated in the tip of the papilla (Fig. 6, $C, D$, and $E$ ). These structures were identified as collecting ducts. In addition we observed a few positively labeled cells in the inner medulla that appear to reside outside tubular structures; t-PA mRNA may therefore also be present in interstitial or other cells.

As suggested by the macroscopic analysis with the ${ }^{32} \mathrm{P}$-labeled probe, glomeruli were found to express moderate amounts of t-PA mRNA (Fig. 6, $A$ and $B$ ). Due to the limitations of morphological resolution on cryostat tissue sections and to the low level of labeling, the positive cells could not be identified with certainty; they could represent endothelial, mesangial, or epithelial cells.

$u-P A$ and $t-P A$ are already synthesized by distinct cells in embryonic nephrons. Hybridizations to whole embryo tissue sections revealed that low amounts of $\mathrm{u}-\mathrm{PA}$ and t-PA mRNAs are already detectable in the kidneys of 15.5-d old embryos (not shown). In 17.5-d old embryos, large amounts of u-PA mRNA were found in the central part of the kidney (Fig. $7 \mathrm{~A}$ ), while moderate amounts of t-PA mRNA were exclusively localized to the cortical area (Fig. $7 \mathrm{~B}$ ). Interestingly, at that stage of development, the kidney represented the site of highest u-PA mRNA abundance in the mouse embryo. Hybridizations with ${ }^{3} \mathrm{H}$-labeled probes showed that u-PA mRNA expression was confined to tubular cells, while t-PA mRNA was detected in epithelial cortical cells, constituting S-shaped bodies (not shown).

Zymographies performed in the presence of plasminogen on corresponding embryo tissue sections displayed a delineated zone of caseinolysis in an area that corresponded to the central part of the kidney (Fig. $7 \mathrm{C}$ ). In the presence of plasminogen and amiloride, a zone of caseinolysis was detected on the cortical area, while no proteolysis could be seen on the central part of the kidney (Fig. $7 \mathrm{D}$ ); anti-u-PA antibodies also abolished the caseinolysis zone corresponding to the central part of the kidney, while the caseinolysis zone on the cortical area was unaffected (not shown). No caseinolysis was detected in the absence of plasminogen (not shown). These findings corroborate mRNA localizations and suggest that both PA mRNAs are translated at this stage of development. Other sites of major plasminogen-dependent caseinolysis were observed, for instance in intracranial structures and in the liver (Fig. 7). Interestingly, neither u-PA nor t-PA mRNAs were detected in the fetal liver, raising the possibility that enzymatic activity might accumulate in the liver via the binding of enzymes to cell-surface receptors $(8,20,21,43)$. This observation illustrates the potential discrepancy between the site of synthesis of a secreted protein and its site(s) of accumulation. 

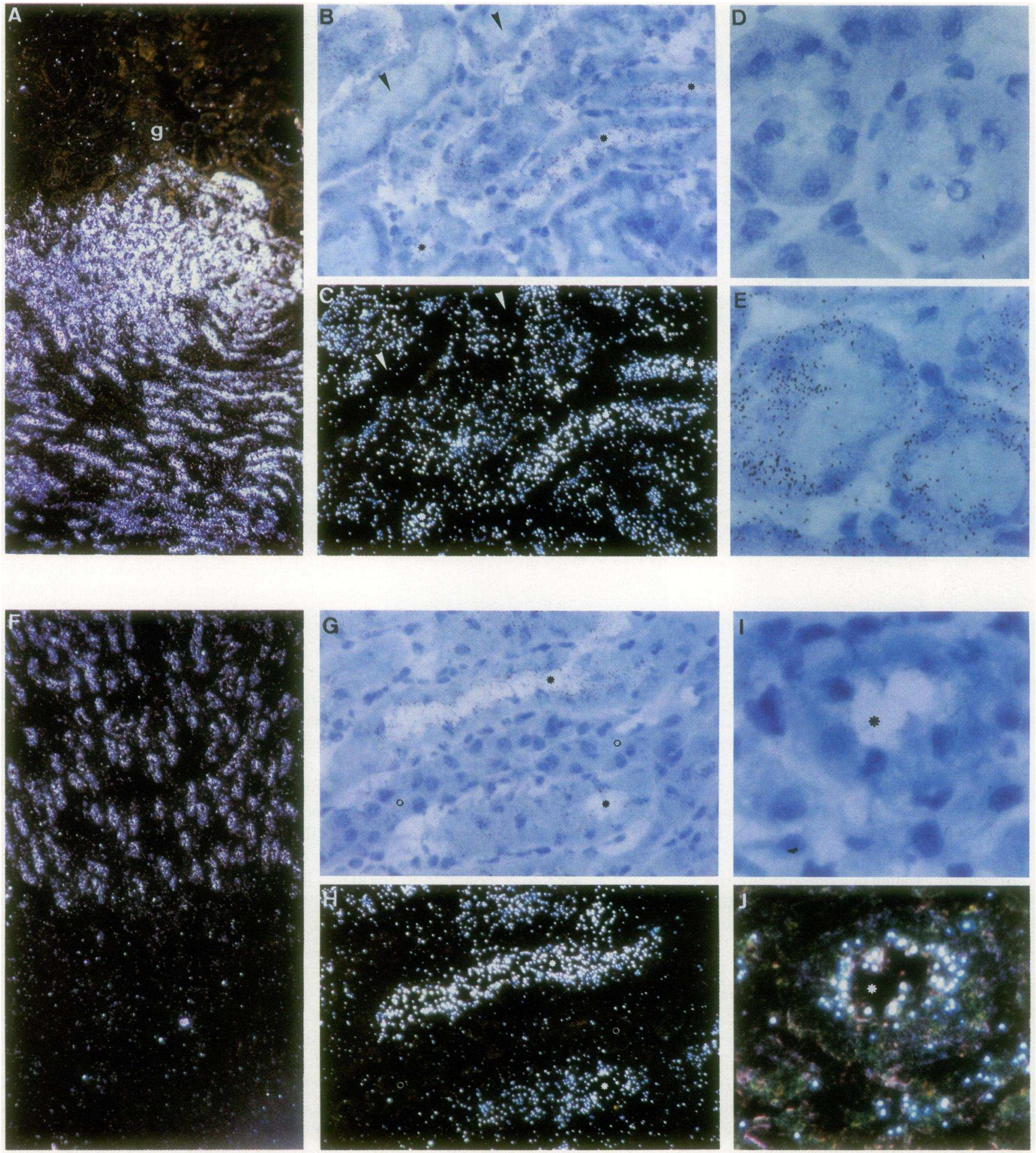

Figure 5. Localization of u-PA mRNA by in situ hybridizations of ${ }^{3} \mathrm{H}$-labeled cRNA probe to cryostat tissue sections of adult kidney. $A, C, F, H$, and $J$ are dark-field micrographs; $B, D, E, G$, and $I$ are light-field micrographs. $C, H, J$ are the corresponding dark-field micrographs of those shown in $B, G$, and $I$, respectively. $A$ to $J$ correspond to different fields of the same section. $(A)$ Cortex, outer and inner stripes of the outer medulla. The expression of u-PA mRNA delineates the cortico-medullary junction (g denotes glomerulus). $(B),(C)$, and $(E)$ Magnifications of the outer stripe of the outer medulla shown in $A$. The straight parts of proximal tubules (arrowheads in $B$ and $C ; E$ ) and of distal tubules (asterisks in $B$ and $C$ ) express u-PA mRNA. Labeling is evenly distributed in the perinuclear cytoplasm of epithelial cells in proximal tubules $(E)$, while grains are concentrated in the apical portion of epithelial cells in distal tubules (asterisks in $B$ and $C$ ). (D) Magnification of the cortex shown in $A$. No signal is observed on convoluted proximal tubules. $(F)$ Inner stripe of outer medulla and inner medulla. The expression of u-PA mRNA is interrupted at the junction between the inner stripe of outer medulla and the inner medulla. $(G),(H),(I)$, and $(J)$ Magnifications of the inner stripe of the outer medulla shown in $F$. The straight parts of distal tubules are labeled, predominantly at their luminal pole $(F$; asterisks in $G, H, I$, and $J$ ), while collecting tubules remain unlabeled (open circles in $G$ and $H$ ). Slides were exposed for 3 wk $(A-J)$. $(A$ and $F, \times 300$; $B, C, G$, and $H, \times 1200 ; D, E, I$, and $J, \times 3,000$.) 

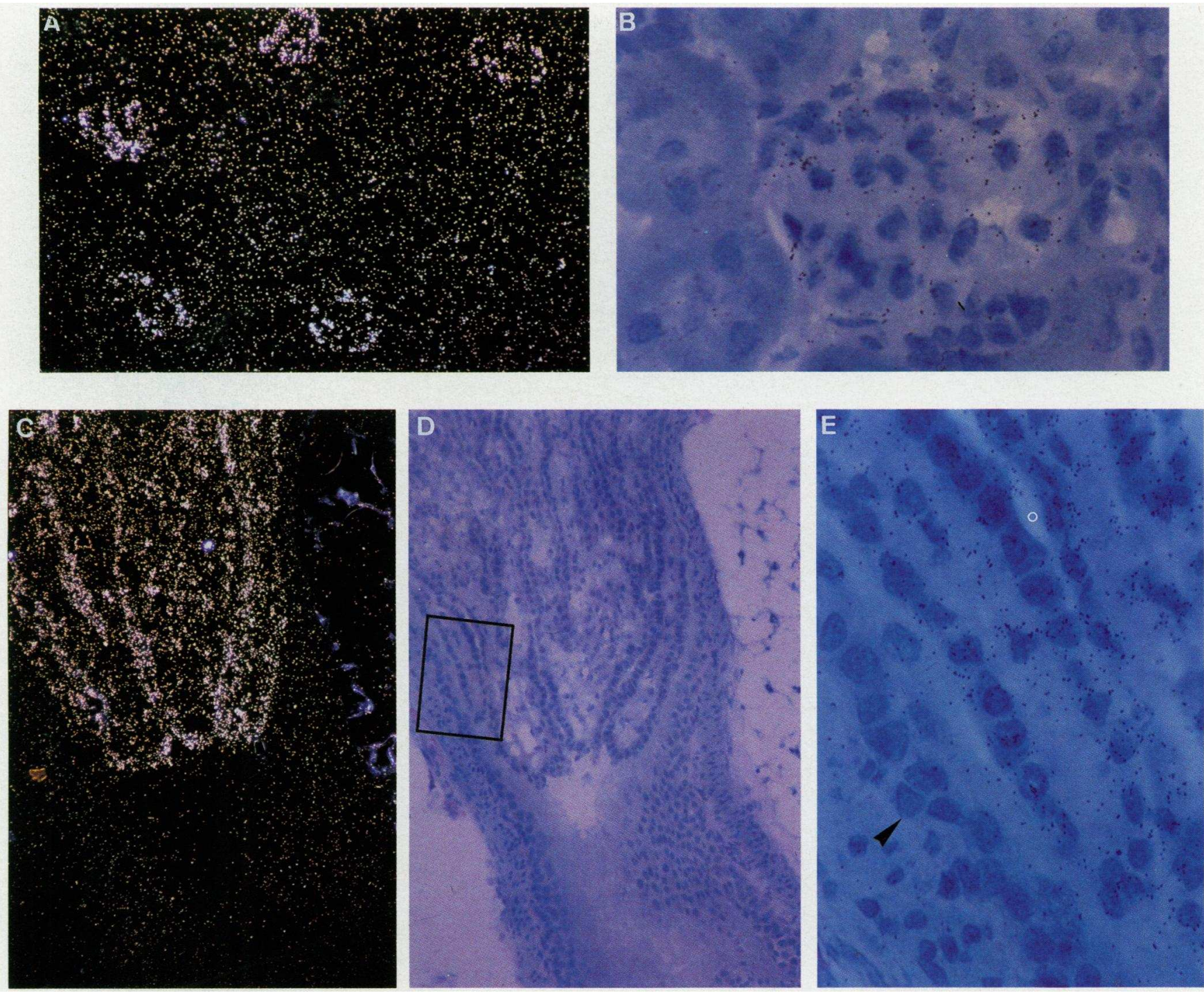

Figure 6. Localization of t-PA mRNA by in situ hybridizations of ${ }^{3} \mathrm{H}$-labeled cRNA probe to cryostat tissue sections of adult kidney. $A$ and $C$ are dark-field micrographs; $B, D$, and $E$ are light-field micrographs. $C$ corresponds to an unstained section adjacent to that shown in $D$. $(A)$ Low magnification view of the cortex. Glomeruli show weak but significant labeling. $(B)$ High magnification of a glomerulus: moderate amounts of t-PA mRNA are expressed by some glomerular cells, while convoluted proximal tubules are unlabeled. $(C)$ and $(D)$ Low magnification view of the tip of the papilla. Most of the labeling is associated with collecting ducts. $(E)$ High magnification of the insert shown in $D$. Collecting ducts are labeled (open circle), while urothelial cells remain unlabeled (arrowhead). Slides were exposed for 15 wk. $(A, C$, and $D, \times 600 ; B$ and $E, \times 3,000$.)

\section{Discussion}

The proteolytic activity of human urine $(44,45)$ and its ability to dissolve fibrin clots $(46,47)$ have been recognized for many years. Fibrinolytic activities, which have since been detected in the various compartments of the urinary tract, have been predominantly ascribed to plasminogen activators (12, 48-52). The kidney is now considered to be a prominent source of u-PA in all mammalian species studied so far $(50,51,53)$. However, the physiological roles of PAs in renal function remain speculative; since many renal disorders are characterized by excessive fibrin deposition, it has been postulated that these enzymes are involved in the prevention of fibrin clot formation $(18,54)$. The precise cellular sites of PA synthesis in the urinary tubules have not been determined, though previous work performed on murine and human tissues, has shown u-PA immu- noreactivity in tubular cells $(15,17)$ and t-PA immunoreactivity in glomerular cells $(16,17)$. To assess the cellular sites of PA production in the murine kidney, we localized PA mRNAs and documented the catalytic activity of PAs on histological sections.

We have shown that, in 17.5-d old mouse embryos, the kidney is the predominant site of u-PA gene expression, and that u-PA is synthesized exclusively by epithelial tubular cells residing in the central part of the kidney. Tissue section zymographies displayed a corresponding zone of plasminogendependent caseinolytic activity that was abolished by specific anti-u-PA antibodies and amiloride, indicating that the detected u-PA mRNA is translated. In the adult kidney, we localized $\mathrm{u}-\mathrm{PA}$ mRNA in the epithelial cells of the straight parts of both proximal and distal tubules, whereas no signal was noticed in convoluted and collecting tubules. Histological zy- 

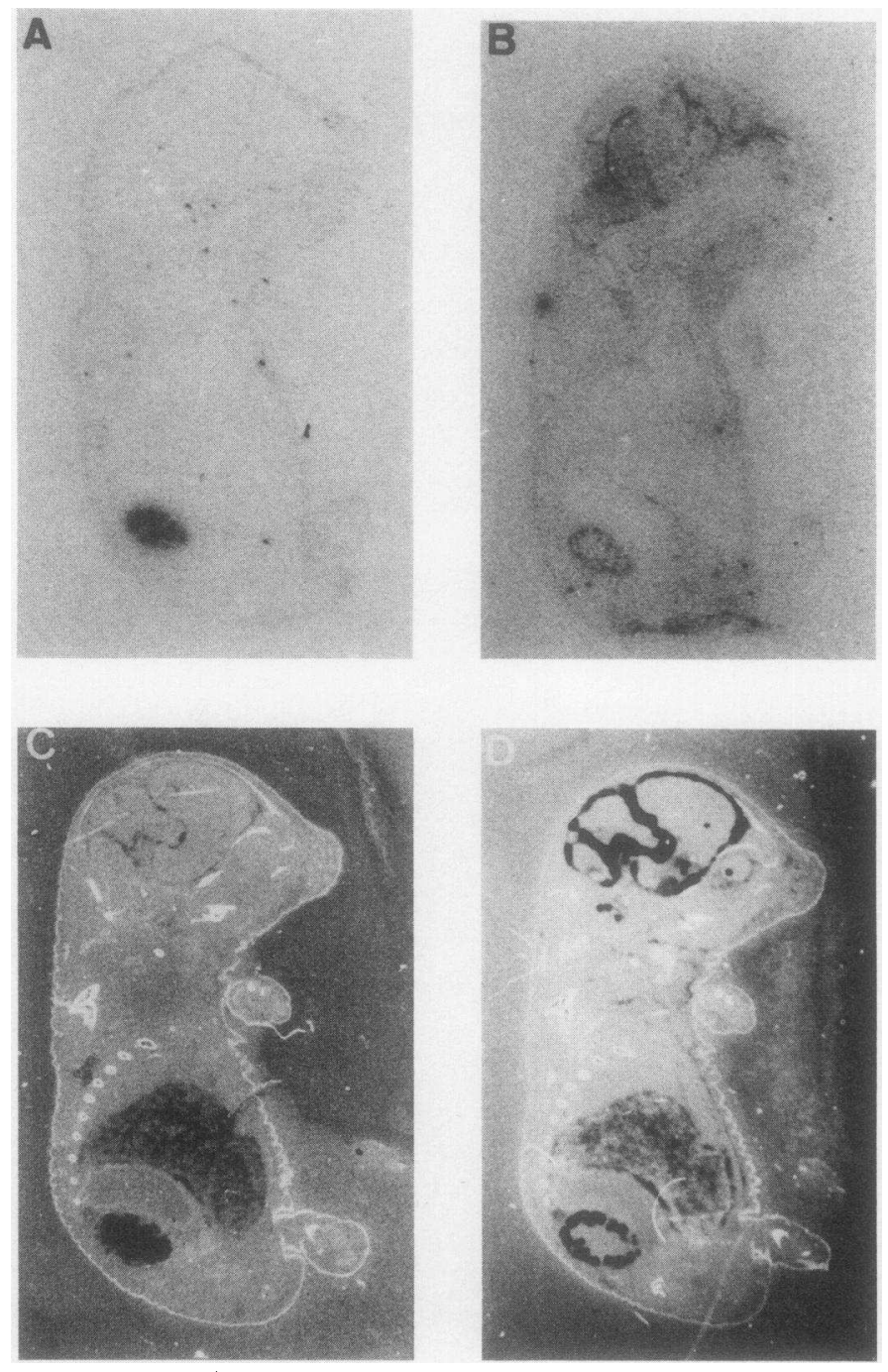

Figure 7. $(A)$ and $(B)$ Regional localization of u-PA $(A)$ and t-PA $(B)$ mRNAs by in situ hybridizations of ${ }^{32} \mathrm{P}$-labeled cRNA probes to cryostat tissue sections of 17.5-d old mouse embryos. Photographs were taken after $72 \mathrm{~h}(A)$ and $120 \mathrm{~h}(B)$ exposure at room temperature $(\times 2.5)$. $(C)$ and $(D)$ Visualization of PA enzymatic activities by histological zymographies on cryostat tissues sections of 17.5-d old mouse embryos. Incubations were performed in the absence $(C)$ or in the presence of $1 \mathrm{mM}$ amiloride $(D)$, which selectively inhibits u-PA (28). In addition to the caseinolytic zones observed over the kidney, plasminogen-dependent proteolytic activity was observed over the liver and the brain. Photographs were taken after $2 \mathrm{~h}(C)$ and $4 \mathrm{~h}(D)$ incubations at $37^{\circ} \mathrm{C}(\times 2.5)$. mographies revealed that $\mathrm{u}-\mathrm{PA}-\mathrm{catalyzed}$ proteolytic activity was restricted to the regions of the kidney in which u-PA mRNA was most abundant. Large amounts of u-PA are recovered in urine, supporting the contention that most of the enzyme synthesized by tubular cells is released in urine; however, our results do not exclude a possible release of u-PA by tubular cells into the vascular compartment, via their basolateral pole, as proposed previously $(16,18,55)$. We were not able to detect the presence of u-PA mRNA in glomerular cells, though u-PA has been identified in extracts of human glomeruli $(16,18,55)$ or in cultures of glomerular epithelial cells (16); this apparent discrepancy might reflect species differences or, alternatively, in vitro differentiation features.

The observed segmental distribution of u-PA production might help define its potential contribution to renal function. The enzyme, which is produced and released by various cell types endowed with migratory and invasive properties, such as monocytes/macrophages $(4,5)$, trophoblasts $(6,7)$, capillary endothelial cells (56), and transformed cells (2), has been predominantly related to tissue remodeling and invasion processes. Differentiated epithelial cells, such as those of the mammary gland, can also synthesize and secrete u-PA in a hormonally regulated fashion $(34,57)$, a finding that has lead to the assumption that $\mathrm{u}-\mathrm{PA}$ might participate in the extensive tissue remodeling that accompanies glandular involution (57). An alternate possibility, supported by work performed on the mammary gland $(58)$ and the vas deferens $(15,35)$, is that $u-P A$ produced by certain epithelial cells might be involved in the maintenance of ductal fluidity. The epithelial cells that synthesize u-PA are located next to tubular segments where major water resorption occurs and which are therefore likely to be particularly exposed to protein precipitation. The u-PA produced and secreted at these sites might provide an efficient proteolytic mechanism to prevent tubular obstruction. This would imply the presence of plasminogen, or alternatively, the direct activity of u-PA on other protein substrates (59) in the urine that reaches the proximal and distal tubules. The presence of plasminogen in the excretory tubules has not been documented, but appropriate amounts of this zymogen might be filtered, transuded, or actively secreted by tubular cells, as previously suggested (55). The presence of active two-chain u-PA and of its $M_{\mathrm{r}} 29,000$ degradation product in urine supports the possibility that plasmin-mediated processes occur in tubules; indeed, plasmin catalyzes both the conversion of prou-PA into active u-PA and the generation of low molecular weight u-PA. Transient hematuria and proteinuria are known 
to occur during extreme physiological conditions, such as strenuous exercise, and numerous renal and systemic diseases are associated with hematuria and proteinuria; clinical studies have reported elevated $\mathrm{u}-\mathrm{PA}$ production in glomerulonephritic patients, when compared with healthy volunteers $(60)$, suggesting that $\mathrm{u}$-PA production might be modulated by protein load in excretory tubules. In the absence of a potent proteolytic system, capable of digesting fibrin and/or other precipitated proteins, individual nephrons may become irreversibly plugged, a damage that, integrated over years, could lead to renal failure; the production of large amounts of u-PA by epithelial tubular cells, starting as soon as the nephron develops, may therefore be required for the preservation of tubule patency.

Maximal t-PA mRNA abundance was observed in distal portions of collecting ducts, which indicates that they are the major source of $t-P A$ production in the kidney. The allocation of t-PA production to tubules has not been reported so far, though studies in dogs have reported PA activity in the tip of the papilla (51). Tissue section zymographies showed the presence of plasminogen-dependent caseinolysis, selectively inhibited by anti-t-PA antibodies, at the sites where t-PA mRNA was detected. Although t-PA was barely detectable in excreted urine, in amounts comparable to those found in excreted human urine (61), zymographic analysis of pelvic urine demonstrated the presence of high amounts of t-PA, providing evidence that the enzyme is secreted in urine and that it may participate in tubular physiology.

In conclusion, we demonstrate here that in the adult mouse kidney u-PA and t-PA are synthesized by distinct epithelial compartments and that both enzymes are secreted in urine. Though the differential distribution of u-PA and t-PA synthesis remains intriguing, these findings suggest that both enzymes may provide means to avoid the deleterious consequences of protein precipitation in tubules.

\section{Acknowledgments}

We thank Dr. J.-A. Schifferli and Dr. M. Amherdt for helpful discussions; Dr. W.-D. Schleuning for the anti-t-PA serum; D. Ducrest and M.-T. Morand for technical assistance; J.-C. Rumbeli, J.-P. Gerber, and G. Negro for photographic work.

This work was supported by grants 32-26941.89 and 3.59-0.87 from the Swiss National Science Foundation, and by the Georg Waechter Memorial Foundation.

\section{References}

1. Reich, E. 1978. Activation of plasminogen: a general mechanism for producing localized extracellular proteolysis. In Molecular Basis of Biological Degradative Processes. R. D. Berlin, H. Hermann, I. H. Lepow, and J. M. Tanzer, editors. Academic Press, Inc., New York. 155-169.

2. Danø, K., P. A. Andreasen, J. Grøndhal-Hansen, P. Kristensen, L. S. Nielsen, and L. Skriver. 1985. Plasminogen activators, tissue degradation, and cancer. Adv. Cancer Res. 44:139-266.

3. Blasi, F., A. Riccio, and G. Sebastio. 1986. Human plasminogen activator. Genes and protein structure. In Human Genes and Diseases. F. Blasi, editor. John Wiley and Sons, Ltd., London.

4. Unkeless, J. C., S. Gordon, and E. Reich. 1974. Secretion of plasminogen activator by stimulated macrophages. J. Exp. Med. 139:834-850.

5. Vassalli, J.-D., J.-M. Dayer, A. Wohlwend, and D. Belin. 1984. Concomitant secretion of prourokinase and of a plasminogen activator-specific inhibitor by cultured human monocytes-macrophages. J. Exp. Med. 159:1653-1668.

6. Strickland, S., E. Reich, and M. I. Sherman. 1976. Plasminogen activator in early embryogenesis: enzyme production by trophoblast and parietal endoderm. Cell. 15:393-403.
7. Sappino, A.-P., J. Huarte, D. Belin, and J.-D. Vassalli. 1989. Plasminogen activators in tissue remodeling and invasion: mRNA localization in mouse ovaries and implanting embryos. J. Cell Biol. 109:2471-2479.

8. Blasi, F., J.-D. Vassalli, and K. Danø. 1987. Urokinase-type plasminogen activator: proenzyme, receptor and inhibitors. J. Cell Biol. 104:801-804.

9. Hoylaerts, M., D. C. Rijken, H. R. Lijnen, and D. Collen. 1982. Kinetics of the activation of plasminogen by human tissue plasminogen activator. J. Biol. Chem. 257:2912-2919.

10. Suenson, E., O. Lützen, and S. Thorsen. 1984. Initial plasmin-degradation of fibrin as the basis of a positive feed-back mechanism in fibrinolysis. Eur. $J$. Biochem. 140:513-522.

11. Kristensen, P., L. I. Larsson, L. S. Nielsen, J. Grøndahl-Hansen, P. A. Andreasen, and K. Danø. 1984. Human endothelial cells contain one type of plasminogen activator. FEBS (Fed. Eur. Biochem. Soc.) Lett. 168:33-37.

12. Sobel, G. W., S. R. Mohler, N. W. Jones, A. Dowdy, and M. M. Guest. 1952. Urokinase: an activator of plasma profibrinolysin extracted from urine. Am. J. Physiol. 171:768-769.

13. Hull, R. N., W. R. Cherry, and G. W. Weaver. 1976. The origin and characteristics of a pig kidney cell strain, LLC-PK . In Vitro (Rockville). 12:670677.

14. Rijken, D. C., D. J. Binnema, and P. Los. 1986. Specific fibrinolytic properties of different molecular forms of pro-urokinase from a monkey kidney cell culture. Thromb. Res. 42:761-768.

15. Larsson, L. I., L. Skriver, L. S. Nielsen, J. Grøndahl-Hansen, P. Kristensen, and K. Danø. 1984. Distribution of urokinase-type plasminogen activator immunoreactivity in the mouse. J. Cell Biol. 98:894-903.

16. Angles-Cano, E., E. Rondeau, F. Delarue, J. Hagege, Y. Sultan, and J. D. Sraer. 1985. Identification and cellular localization of plasminogen activators from human glomeruli. Thromb. Haemostasis. 54:688-692.

17. Saksela, O., and H. Holthöfer. 1987. Plasminogen activators during differentiation of the human kidney. Differentiation. 34:131-138.

18. Bergstein, J. M., M. Riley, and N. U. Bang. 1988. Analysis of the plasminogen activator activity of the human glomerulus. Kidney Int. 33:868-874.

19. Salonen, E.-M., A. Zitting, and A. Vaheri. 1984. Laminin interacts with plasminogen and its tissue-type activator. FEBS (Fed. Eur. Biochem. Soc.) Lett. 172:29-32.

20. Vassalli, J.-D., D. Baccino, and D. Belin. 1985. A cellular binding site for the $M_{\mathrm{r}} 55,000$ form of the human plasminogen activator, urokinase. J. Cell Biol. 100:86-92.

21. Stoppelli, M. P., A. Corti, A. Soffientini, G. Cassani, F. Blasi, and R. K. Assoian. 1985. Differentiation-enhanced binding of the amino-terminal fragment of human urokinase plasminogen activator to a specific receptor on U-937 monocytes. Proc. Natl. Acad. Sci. USA. 82:4939-4943.

22. Baker, J. B., D. A. Low, R. L. Simmer, and D. D. Cunningham. 1980. Protease-nexin: a cellular component that links thrombin and plasminogen activator and mediates their binding to cells. Cell. 21:37-45.

23. Loskutoff, D. J., J. A. van Mourik, L. A. Erickson, and D. Lawrence. 1983. Detection of an unusually stable fibrinolytic inhibitor produced by bovine endothelial cells. Proc. Natl. Acad. Sci. USA. 80:2956-2960.

24. Lecander, I., and B. Astedt. 1986. Isolation of a new plasminogen activator inhibitor from pregnancy plasma. Br. J. Haematol. 62:221-228.

25. Theiler, K. 1989. The House Mouse. Development and Normal Stages from Fertilization to 4 Weeks of Age. Springer-Verlag, Berlin, Heidelberg, New York.

26. Huarte, J., D. Belin, and J.-D. Vassalli. 1985. Plasminogen activator in mouse and rat oocytes: induction during meiotic maturation. Cell. 43:551-558.

27. Vassalli, J.-D., J. Hamilton, and E. Reich. 1977. Macrophage plasminogen activator: induction by concanavalin $\mathrm{A}$ and phorbol myristate acetate. Cell. 11:695-705.

28. Vassalli, J.-D., and D. Belin. 1987. Amiloride selectively inhibits the urokinase-type plasminogen activator. FEBS (Fed. Eur. Biochem. Soc.) Lett. 214:187191.

29. Marotti, K. R., D. Belin, and S. Strickland. 1982. The production of distinct forms of plasminogen activator by mouse embryonic cells. Dev. Biol. 90:154-159.

30. Belin, D., F. Godeau, and J.-D. Vassalli. 1984. Tumor-promoter PMA stimulates the synthesis and secretion of mouse pro-urokinase in MSV-transformed 3T3 cells: this is mediated by an increase in urokinase mRNA content. EMBO (Eur. Mol. Biol. Organ.) J. 3:1901-1906.

31. Belin, D., J.-D. Vassalli, C. Combépine, F. Godeau, Y. Nagamine, E. Reich, H. P. Kocher, and R. M. Duvoisin. 1985. Cloning, nucleotide sequencing and expression of $\mathrm{cDNAs}$ encoding mouse urokinase-type plasminogen activator. Eur. J. Biochem. 148:225-232.

32. Rickles, R. J., A. L. Darrow, and S. Strickland. 1988. Molecular cloning of complementary DNA to mouse tissue plasminogen activator mRNA and its expression during F9 teratocarcinoma cell differentiation. J. Biol. Chem. 263:15631569.

33. Sappino, A.-P., N. Busso, D. Belin, and J.-D. Vassalli. 1987. Increase of urokinase-type plasminogen activator gene expression in human lung and breast carcinomas. Cancer Res. 47:4043-4046. 
34. Busso, N., D. Belin, C. Failly-Crépin, and J.-D. Vassalli. 1986. Plasminogen activators and their inhibitors in a human mammary cell line (HBL-100). Modulation by glucocorticoids. J. Biol. Chem. 261:9309-9315.

35. Huarte, J., D. Belin, D. Bosco, A.-P. Sappino, and J.-D. Vassalli. 1987. Plasminogen activator and mouse spermatozoa: urokinase synthesis in the male genital tract and binding of the enzyme to the sperm cell surface. J. Cell Biol. 104:1281-1289.

36. Kielberg, V., P. A. Andreasen, J. Grøndahl-Hansen, L. S. Nielsen, L. Skriver, and K. Danø. 1985. Proenzyme to urokinase-type plasminogen activator in the mouse in vivo. FEBS (Fed. Eur. Biochem. Soc.) Lett. 182:441-445.

37. Rickles, R., and S. Strickland. 1988. Tissue plasminogen activator mRNA in murine tissues. FEBS (Fed. Eur. Biochem. Soc.) Lett. 229:100-106.

38. Chao, J. 1983. Purification and characterization of rat urinary esterase A, a plasminogen activator. J. Biol. Chem. 258:4434-4439.

39. Fuller, P. J., and J. W. Funder. 1986. The cellular physiology of glandular kallikrein. Kidney Int. 29:953-964.

40. Margolius, H. S., and J. Chao. 1980. Amiloride inhibits mammalian renal kallikrein and a kallikrein-like enzyme from toad bladder and skin. J. Clin. Invest. $65: 1343-1350$.

41. Figueroa, C. D., I. Caorsi, J. Subiabre, and C. P. Vio. 1984. Immunoreactive kallikrein localization in the rat kidney: an immuno-electron-microscopic study. J. Histochem. Cytochem. 32:117-121.

42. Xiong, W., L. Chao, and J. Chao. 1989. Renal kallikrein mRNA localization by in situ, hybridization. Kidney Int. 35:1324-1329.

43. Kuiper, J., M. Otter, D. C. Rijken, and T. J. van Berkel. 1988. Characterization of the interaction in vivo of tissue-type plasminogen activator with liver cells. J. Biol. Chem. 263:18220-18224.

44. Brücke, E. 1861. Beiträge zur Lehre von der Verdauung. Sitzungsber. Math.-Nat. Wiss. (Wien). 43:601-623.

45. Sahli, W. 1885. Uber das Vorkommen von Pepsin und Trypsin im normalen menschlichen Harn. Pfluegers Arch. Gesamte Physiol. Menschen Tiere. 36:209-229.

46. McFarlane, R. G., and J. Pilling. 1947. Fibrinolytic activity of normal urine. Nature (Lond.). 159:779.

47. Williams, J. R. 1951. The fibrinolytic activity of urine. Br. J. Exp. Pathol. $32: 530-537$
48. Mohler, S. R., D. R. Celander, and M. Guest. 1958. Distribution of urokinase among mammals. Am. J. Physiol. 192:186-190.

49. Ladehof, A. A. 1960. The content of plasminogen activator in the human urinary tract. Scand. J. Clin. Lab. Invest. 12:136-139.

50. Todd, A. S. 1964. Localization of fibrinolytic activity in tissues. Br. Med. Bull. 20:210-212.

51. McConnel, D., J. G. Johnston, I. Young, and R. Holemans. 1966. Localization of plasminogen activator in kidney tissue. Lab. Invest. 15:980-986.

52. Granelli-Piperno, A., and E. Reich. 1978. A study of proteases and protease-inhibitor complexes in biological fluids. J. Exp. Med. 148:223-234.

53. Hart, D., A. Rehetmulla, and E. Babins. 1986. Species differences in the detection of high molecular weight urinary plasminogen activators. Comp. Biochem. Physiol. 84B:287-293.

54. Vassalli, P., and R. T. McCluskey. 1971. The pathogenetic role of the coagulation process in glomerular diseases of immunological origin. Adv. Nephrol. Necker Hosp. 1:47-63.

55. Muellbacher, W., M. Maier, and B. R. Binder. 1989. Regulation of plasminogen activation in isolated perfused rat kidney. Am. J. Physiol. 256:F787793.

56. Pepper, M. S., J.-D, Vassalli, R. Montesano, and L. Orci. 1987. Urokinase-type plasminogen activator is induced in migrating capillary endothelial cells. J. Cell Biol. 105:2535-2541.

57. Ossowski, L., D. Biegel, and E. Reich. 1979. Mammary plasminogen activator: correlation with involution, hormonal modulation and comparison between normal and neoplastic tissues. Cell. 16:929-940.

58. Busso, N., J. Huarte, J.-D. Vassalli, A.-P. Sappino, and D. Belin. 1989. Plasminogen activators in the mouse mammary gland. Decreased expression during lactation. J. Biol. Chem. 264:7455-7457.

59. Gold, L. I., R. Schwimmer, and J. P. Quigley. 1989. Human plasma fibronectin as a substrate for human urokinase. Biochem. J. 262:529-534.

60. Takada, A., K. Sakakibara, M. Nagase, K. Shizume, and Y. Takada. 1986. Determination of urokinase in the urine of healthy volunteers and patients with renal diseases. Thromb. Res. 44:867-873.

61. Rijken, D. C., C. Wijngaards, and J. Welbergen. 1981. Immunological characterization of plasminogen activator activities in human tissues and body fluids. J. Lab. Clin. Med. 97:477-486. 